\title{
Prenatal diagnosis of the 22q11.2 deletion syndrome
}

Deborah A. Driscoll, $M D$

\begin{abstract}
The development of fluorescence in situ hybridization (FISH)- and polymerase chain reaction (PCR)-based assays for the detection of deletions of chromosome 22q11.2 has enabled the medical community to offer couples at risk prenatal diagnostic testing. Current indications for testing include a previous child with a 22q11.2 deletion or DiGeorge/velocardiofacial syndrome, an affected parent with a 22q11.2 deletion, and in utero detection of a conotruncal cardiac defect. Antenatal knowledge of the deletion status provides couples and clinicians with an accurate diagnosis, prognostic information, and recurrence risk, which may assist couples with their reproductive decisions. However, there are limitations to prenatal testing, which should be reviewed prior to testing. Genetics
\end{abstract} in Medicine, 2001:3(1):14-18.

Key Words: prenatal diagnosis, 22q11.2 deletion, conotruncal cardiac defect, fetal echocardiography

The majority of patients with DiGeorge and velocardiofacial syndrome (DGS/VCFS) have large interstitial deletions of chromosomal region 22q11.2. ${ }^{1}$ In addition, several studies have demonstrated that a significant percentage of cardiac patients with conotruncal cardiac malformations have a 22q11.2 deletion. ${ }^{2-5}$ Although DGS/VCFS were initially considered rare disorders, recent studies suggest that the 22q11.2 deletion may occur as frequently as 1 in 4000 live births. ${ }^{6}$ Deletions of 22q11.2 have also been detected in patients with conotruncal anomaly face syndrome and in some patients with OpitzG/ BBB and Cayler cardiofacial syndrome. ${ }^{7-9}$ These disorders, collectively referred to as the 22q11.2 deletion syndrome, are predominantly characterized by congenital cardiac defects, immune deficiencies secondary to aplasia or hypoplasia of the thymus, hypocalcemia due to small or absent parathyroid glands, palatal and speech abnormalities, and cognitive difficulties. Large clinical studies and case reports have shown that the phenotypic features seen in patients with the 22q11.2 deletion are much more variable and extensive than previously recognized, and include developmental problems, feeding difficulties, neurologic, ocular, psychiatric, renal, and skeletal abnormalities. ${ }^{10-13}$ Although the majority of deletions are de novo, the deletion can be transmitted as an autosomal dominant; hence, individuals with a 22q11.2 deletion have a $50 \%$ risk of having an affected offspring in each pregnancy. Familial deletions have been identified in $8-28 \%$ of probands. ${ }^{11,12}$ The development of fluorescence in situ hybridization (FISH)- and

\footnotetext{
From the Division of Reproductive Genetics, Department of Obstetrics and Gynecology, University of Pennsylvania; Division of Human Genetics and Molecular Biology, Department of Pediatrics, The Children's Hospital of Philadelphia, Philadelphia, Pennsylvania.

Deborah A. Driscoll, MD, Division of Reproductive Genetics, Department of Obstetrics and Gynecology, 3400 Spruce Street, Philadelphia, PA 19104.

Received: August 8, 2000.

Accepted: October 16, 2000.
}

polymerase chain reaction (PCR)-based assays for the detection of deletions of chromosome 22q11.2 has enabled the medical community to offer couples at risk prenatal diagnostic testing. ${ }^{14-20}$

\section{INDICATIONS FOR PRENATAL TESTING}

Current indications for prenatal testing for the $2 \mathrm{q} 11.2$ deletion include (1) a previous child with a 22q11.2 deletion or DiGeorge/velocardiofacial syndrome, (2) an affected parent with a 22q11.2 deletion, and (3) in utero detection of a fetus with a conotruncal cardiac defect. The risk for unaffected parents of having another child with the 22q11.2 deletion is presumably low; however, prenatal testing for the deletion is offered because of the possibility of germline mosaicism. Germline mosaicism for intragenic deletions has been reported for several genetic disorders, including the 22q11.2 deletion. ${ }^{21}$ In cases for which a deceased child with features suggestive of DGS/VCFS was not tested for the deletion, a careful evaluation of the parents for the presence of mild phenotypic features and 22q11.2 deletion testing is recommended. These parents may elect prenatal testing with the understanding that the interpretation of negative test results is limited. The etiology of DGS/VCFS is heterogeneous; $10-15 \%$ of individuals with characteristic features do not have a $22 \mathrm{q} 11.2$ deletion. ${ }^{1}$ Therefore, prenatal testing for the deletion is not helpful for couples with affected offspring without evidence of a 22q11.2 deletion. In contrast, affected parents and patients have a $50 \%$ chance of transmitting the deletion to their offspring in each pregnancy and may proceed with prenatal testing to make informed reproductive decisions.

Since the 22q11.2 deletion has been shown to be one of the most commonly recognized causes of conotruncal cardiac defects, testing for the 22q11.2 deletion should be considered, in addition to a fetal karyotype, when a cardiac defect is detected 
in utero by fetal echocardiography. This is particularly true for cardiac lesions with a high frequency of the deletion including interrupted aortic arch $(50-80 \%)$ and truncus arteriosus $(35 \%)$. The deletion is less commonly found in patients with tetralogy of Fallot (15\%) and rare in double outlet right ventricle and transposition of the great vessels. ${ }^{2-5}$ Several reports have demonstrated the utility of antenatal testing for the $22 \mathrm{q} 11.2$ deletion when a congenital heart defect is identified in utero. ${ }^{14-19,23}$ The majority of these fetuses had either an outflow tract or aortic arch malformation, although Raymond et al. also identified a 22q11.2 deletion in one fetus with an atrioventricular septal defect and double outlet right ventricle. ${ }^{16}$

Sonographic demonstration of associated anomalies, including cleft palate, polyhydramnios, renal, or skeletal anomalies, may raise the suspicion of a 22q11.2 deletion in a fetus with any type of cardiac defect. Although palatal abnormalities are a common feature in the 22q11.2 deletion syndrome, overt cleft palate or cleft lip, which may be detected antenatally by ultrasonography, occur in $<12 \%$ of patients. ${ }^{12}$ The $22 \mathrm{q} 11.2$ deletion has not been found to be a cause of nonsyndromic cleft palate; hence, prenatal testing is not recommended in the absence of other findings. ${ }^{22}$ Polyhydramnios can be associated with several anomalies common to the 22q11.2 deletion syndrome, including cardiac defects, cleft palate, and swallowing difficulties. Prenatal detection of a 22q11.2 deletion has been reported in a fetus with polyhydramnios and tetralogy of Fallot. ${ }^{23}$ Retrospectively, polyhydramnios of variable severity and onset was documented in 8 of 52 cases subsequently found to have 22q11.2 deletion. Six of the eight had structural anomalies, including cardiac defects, hydronephrosis, and cleft palate; all 8 developed severe postnatal feeding difficulties. ${ }^{23}$ Hence, the finding of polyhydramnios in a fetus with a 22q11.2 deletion should alert the medical team and family to the possibility of severe feeding difficulties. Skeletal anomalies of the extremities such as pre- and postaxial polydactyly, club hands and feet, and syndactyly occur in approximately $15 \%$ of patients. Renal anomalies, including renal agenesis, multicystic kidneys, hydroureter with hydronephrosis, have been reported in as high as $37 \%$ of deleted patients. ${ }^{11,12}$ Although these skeletal and renal anomalies may be recognized antenatally by sonographic examination, the incidence of the $22 \mathrm{q} 11.2$ deletion in patients with these anomalies in the absence of a cardiac defect remains to be determined but, is presumably low. ${ }^{24}$ Therefore, the decision to offer prenatal testing for the $22 \mathrm{q} 11.2$ deletion should be based on the finding of either a cardiac defect or two or more associated anomalies and family history.

Family history is very important in assessing the risk of a 22q11.2 deletion in the fetus. Recent studies have demonstrated that affected parents are often overlooked because of the mild presentation but, in fact, often report learning difficulties, hypernasal speech and have mild dysmorphic facial features consistent with the 22q11.2 deletion syndrome. ${ }^{25,26}$ Hence, close attention should be paid to the parent's past school performance, need for speech therapy, evidence of hypernasal speech, and the presence of classic facial characteristics such as protuberant ears with overfolded helices, hypoplas- tic alae nasae, bulbous nasal tip, prominent nasal root, "hooded eyelids," and long face with malar flattening (Fig. 1). Although the facial features can provide a clue to the diagnosis, they can also be quite subtle and variable.

The deletion has also been reported in an infant with nuchal translucency at 12-13 weeks gestation that was subsequently found at birth to have an interrupted aortic arch. ${ }^{27}$ Since nuchal translucency can be seen in association with cardiac defects and given the high frequency of cardiac defects in the 22q11.2 deletion syndrome, this is not an unexpected finding. At the present time, 22q11.2 deletion testing is not recommended until fetal echocardiography has been performed to document the presence of a cardiac defect. However, since chorionic villus sampling (CVS) or amniocentesis are often performed to diagnose fetal anueploidy when the fetus has nuchal translucency, the laboratory may want to consider saving the cultured cells for FISH analysis in the event that a cardiac defect is subsequently found. ${ }^{27}$

\section{DETECTION OF THE 22q11.2 DELETION}

The most widely utilized method for detecting the 22q11.2 deletion is FISH with probes from the DiGeorge chromosomal

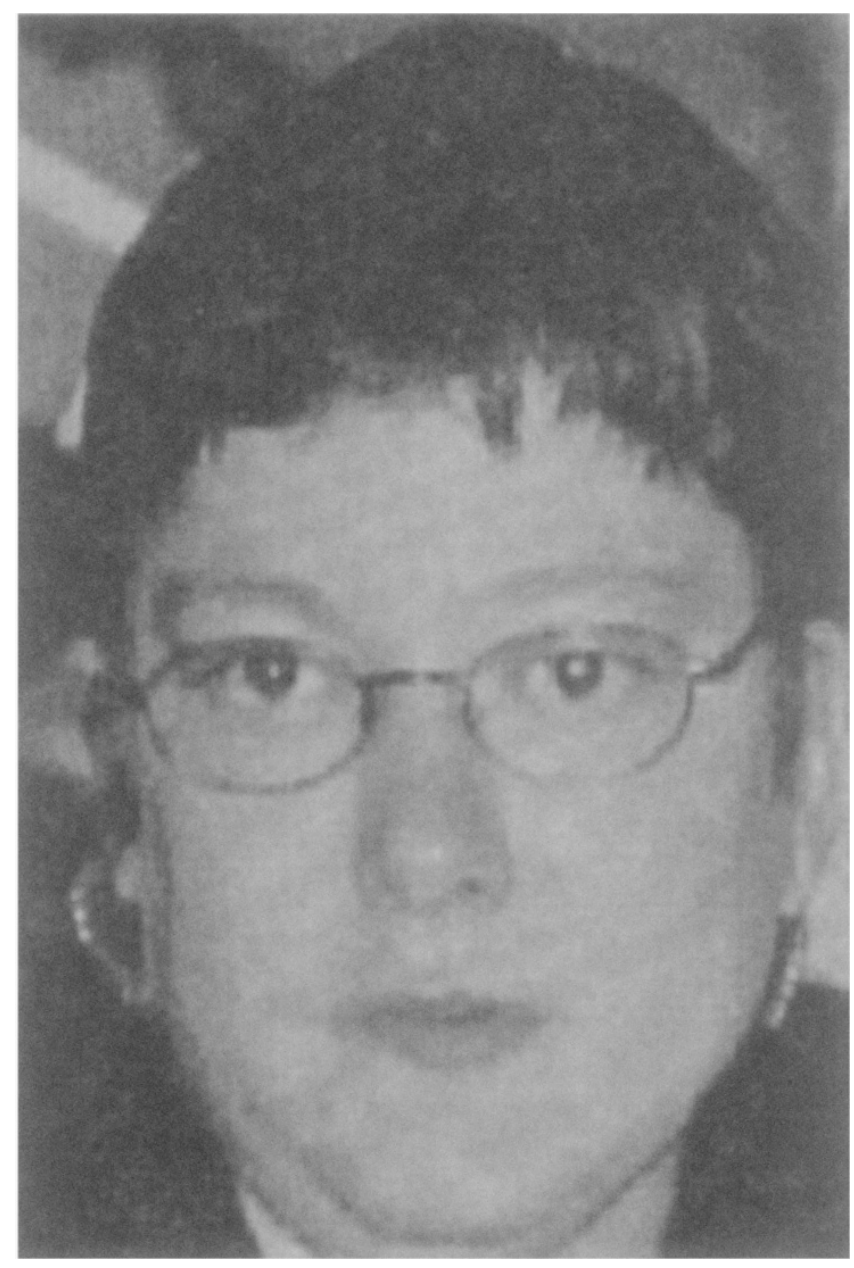

Fig. 1 Frontal view of young adult with the 22q11.2 deletion demonstrating bulbous nasal tip with hypoplastic alae nasae, micrognathia, and thick overfolded helices. 
region (DGCR). Prenatal detection of the $22 \mathrm{q} 11.2$ deletion is usually performed on metaphase chromosomes from either cultured amniocytes obtained by amniocentesis after 15 weeks gestation or cultured chorionic villi obtained by CVS at 10-12 weeks gestation. Occasionally, cytogenetic analysis will demonstrate an unbalanced translocation or an interstitial deletion of 22q11.2. However, the sensitivity is low; therefore, most cytogenetic laboratories rely almost exclusively on FISH to evaluate the at-risk pregnancy. Preimplantation genetic diagnosis by FISH has also been reported in an at-risk mother with a 22q11.2 deletion. ${ }^{28}$ This may be an attractive option for some couples with a $50 \%$ risk of transmitting the deletion who wish to avoid having an affected child and would not consider prenatal testing and termination of an affected pregnancy.

Alternatively, DNA-based assays can be used to demonstrate failure to inherit a parental allele or hemizygosity in the deleted region. Restriction fragment length polymorphism (RFLP) analysis and quantitative hybridization have been used in the past. ${ }^{29}$ More recently, PCR assays using short tandem repeat polymorphisms (STRPs) within the DGCR have been developed and utilized for diagnostic purposes. ${ }^{30,31}$ PCR assays are attractive for prenatal testing, since genotyping can be performed rapidly using uncultured villi or amniotic fluid. Furthermore, they may be utilized by molecular diagnostic laboratories that lack the ability to perform FISH. However, a complete evaluation of the fetus with a cardiac malformation should include a karyotype to exclude aneuploidy or other chromosomal rearrangements; PCR may be used as a rapid adjunct to cytogenetic analysis.

Ultrasonography and fetal echocardiography may identify a fetus at risk for the 22q11.2 deletion. However, these are not considered diagnostic tests. Once a conotruncal cardiac defect with or without associated anomalies has been identified, deletion testing is recommended. Some of the anomalies reported in the 22q11.2 deletion syndrome may also be detected by ultrasonographic examination. However, these are nonspecific findings and if seen in combination with either a cardiac defect or other associated anomalies should prompt further evaluation for the presence of a 22q11.2 deletion.

\section{BENEFITS OF PRENATAL TESTING FOR THE 22q11.2 DELETION}

For unaffected parents with a previous child with a $22 \mathrm{q} 11.2$ deletion, prenatal testing usually provides reassurance. Couples at high risk for transmitting a familial deletion may base their decision whether to continue the pregnancy or the type of obstetric and pediatric care they require on prenatal test results. When a fetal cardiac defect is identified, antenatal knowledge of the fetal deletion status provides couples and clinicians with an accurate diagnosis. The finding of a 22q11.2 deletion enables clinicians to provide a couple with an accurate assessment of their recurrence risk and to determine whether other relatives are at risk. Furthermore, they can provide prognostic information, including cognitive and developmental profiles based on data collected from large clinical studies of individu- als with the 22q11.2 deletion, which will enable the couple to make an informed reproductive decision. ${ }^{10-13,32,33}$ Couples and their physicians can prepare for the delivery of a child with the deletion and anticipate associated problems such as hypocalcemia, immune deficiencies, and feeding difficulties in the newborn period. Delivery at a tertiary care center should also be considered, especially when a complex cardiac lesion is detected antenatally. Infants and children with 22q11.2 deletions may benefit from early intervention based on the evaluation and long-term care by a multidisciplinary team of pediatric specialists aware of the wide spectrum of medical, neuropsychologic, and cognitive problems these children can encounter. Parent support groups are available in the United States, Canada, Europe, and Australia, as well as on-line and can provide families with additional information and support.

\section{LIMITATIONS OF PRENATAL TESTING FOR THE 22q11.2 DELETION}

FISH is a highly accurate test for detecting the standard 22q11.2 deletion when a couple has had a previous child with the deletion or a parent has the deletion. However, DGS/VCFS is a heterogeneous disorder and $10-15 \%$ of individuals with the characteristic features do not have the standard 22q11.2 deletion. Hence, prenatal testing for the detection of a 22q11.2 deletion is of limited value for couples who have had a previous affected child without a deletion. Several other genetic causes of DGS/VCFS have been identified in these individuals, including interstitial deletions of the short arm of chromosome 10 and long arm of chromosome 4, unbalanced chromosomal translocations, and atypical deletions of 22q11.2. ${ }^{34-40}$ These atypical deletions of 22q11 have not been detected by FISH using commercially available probes. Although numerous genes in the commonly deleted region of 22q11.2 have been identified, there has been only a single case report of a small intragenic deletion in UFDIL. ${ }^{41}$ At the present time, no laboratory has identified point mutations in any other gene in the region in nondeleted patients with DGS/VCFS. ${ }^{42}$

The etiology of congenital heart defects (CHD) is heterogeneous; in addition to the 22q11.2 deletion, other causes must be considered, including aneuploidy, other single gene defects, maternal disease states such as diabetes, and exposure to teratogens. The detection rate for the 22q11.2 deletion in a fetus with a conotruncal cardiac defect depends on the type of lesion and the accuracy of the fetal echocardiogram. Based on postnatal studies the detection rate for the 22q11.2 deletion in interrupted aortic arch and truncus arteriosus is high, 50-80\% and $35 \%$, respectively. The detection rate is lower for other types of conotruncal cardiac malformations, in particular, double outlet right ventricle and transposition of the great vessels. Furthermore, the sensitivity of detailed fetal echocardiography for the detection of a CHD is approximately $70 \%$ but, varies widely from 51 to $91 \%$. The detection rate based on routine ultrasound examination is much lower, 10 to $20 \%{ }^{43}$ Couples should receive counseling regarding the potential causes of CHD, limitations of echocardiography, and the ac- 
curacy of deletion testing prior to consenting to the procedure and testing.

Another major limitation of prenatal testing is our inability to accurately predict the phenotype antenatally. Studies indicate that there is no correlation between the phenotype and the extent or size of the $22 \mathrm{q} 11.2$ deletion. ${ }^{44-46}$ The severity cannot be assessed prenatally. Studies of familial deletions demonstrate significant intrafamilial variability; hence, the parental phenotype is not a reliable predictor of outcome in the fetus. ${ }^{25,26}$ Ultrasonography and fetal echocardiography may be helpful in further defining the phenotype. The identification of a cardiac defect provides clinicians with information, which may be useful in the management of the pregnancy and the neonate. However, fetal echocardiography may not identify all structural lesions prenatally and abnormalities of the outflow tract and aberrant vessels commonly seen in association with the 22q11.2 deletion may be missed. Hence, a postnatal cardiac evaluation is recommended. The clinical presentation of the 22 q11.2 deletion is highly variable and includes many features which cannot be evaluated prenatally but require long-term prospective evaluation by a multidisciplinary team of pediatric specialists.

\section{SUMMARY}

Prenatal testing for the 22q11.2 deletion should be offered to couples based on their family history of a previous child with the deletion or features of DGS/VCFS, a parent with the deletion, or when a conotruncal cardiac defect is identified antenatally. Pretest counseling should include a risk assessment based on the family history or the frequency of the deletion in patients with conotruncal cardiac defects. Couples should also receive information about the $22 \mathrm{q} 11.2$ deletion syndrome and be informed of the variability and prognosis. Prior to testing for the deletion, couples should be counseled about the benefits and limitations of testing. Written informed consent should always be obtained from couples electing to undergo either CVS or amniocentesis. When a deletion is detected, couples benefit from post-test counseling to review the phenotypic variability, the implications of having a child with the 22q11.2 deletion, and the current testing limitations. Parents may benefit from speaking with a geneticist with expertise in the 22 q11.2 deletion syndrome or with parents of children with the 22q11.2 deletion through the local or on-line support groups. This information may be helpful for couples in considering their pregnancy options.

\section{Acknowledgments}

This work was supported in part by grants DC02027 and HL51533 from the National Institutes of Health.

\section{References}

1. Driscoll DA, Salvin J, Sellinger B, McGinn-McDonald D, Zackai EH, Emanuel BS Prevalence of 22q11 microdeletions in DGS and VCFS: implications for genetic counseling and prenatal diagnosis. J Med Genet 1993;30:813-817.

2. Goldmuntz E, Clark BJ, Mitchell LE, Jawad AF, Reed L, McDonald-McGinn DM, Cuneo BF, Chien P, Feuer J, Zackai EH, Emanuel BS, Driscoll DA. Frequency of 22q11 deletions in patients with conotruncal defects. J Am Coll Cardiol 1998;32:492_498.

3. Lewin MB, Lindsay EA, Jurecic V, Goytia V, Towbin JA, Baldini A. A genetic etiology for interruption of the aortic arch type B. Am J Cardiol 1997;80:493-497.

4. Takahashi K, Kido S, Hoshino K, Ogawa K, Ohashi H, Fukushima Y. Frequency of a 22q11 deletion in patients with conotruncal cardiac malformations: a prospective study. Eur J Pediatr 1995;154:878-881.

5. Webber SA, Hatchwell E, Barber JCK, Daubeney PEF, Crolla JA, Salmon AP, Keeton BR, Temple IK, Dennis NR. Importance of microdeletions of chromosomal region $22 \mathrm{q} 11$ as a cause of selected malformations of the ventricular outflow tracts and aortic arch: a three year prospective study. J Pediatr 1996;129:26-32.

6. Devriendt K, Fryns J-P, Mortier G, Van Thienen M-N, Keymolen K. The annual incidence of DiGeorge/velocardiofacial syndrome. J Med Genet 1998;35:789-790.

7. Burn J, Takao A, Wilson D. Conotruncal anomaly face syndrome is associated with a deletion within chromosome 22. J Med Genet 1993;30:822-824.

8. McDonald-McGinn DM, Driscoll DA, Bason L, Christensen K, Lynch D, Sullivan K, Canning D, Zavod W, Quinn N, Rome J et al. Autosomal dominant “Opitz GBBB syndrome due to a 22q11.2 deletion. Am J Med Genet 1995;59:103-113.

9. Bawle EV, Conard J, Van Dyke DL, Czarnecki P, Driscoll DA. Seven new cases of Cayler cardiofacial syndrome with 22q11.2 deletion, including a familial case [Letter]. Am J Med Genet 1998;79:406-410.

10. McDonald-McGinn DM, LaRossa D, Goldmuntz E, Sullivan K, Eicher P, Gerdes M, Moss E, Wang PP, Solot C, Schultz P, Lynch D, Bingham P, Keenan G, Weinzimer S, Ming JE, Driscoll D, Clark BJ, Markowitz R, Cohen A, Moshang T, Pasquariello P, Randall P, Emanuel BS, Zackai EH. The 22q11.2 deletion: screening for deletion, diagnostic workup, and outcome of results: report on 181 patients. Genet Test 1997; 1:99-107.

11. Ryan AK, Goodship JA, Wilson DI, Philip N, Levy A, Seidel H, Schuffenhauer S, Oechsler H, Belohradsky B, Prieur M, Aurias A, Raymond FL, Clayton-Smith J, Hatchwell E, McKeown C, Beemer FA, Dallapiccola B, Novelli G, Hurst JA, Ignatius J, Green AJ, Winter RM, Brueton L, Brondum-Nielsen K, Stewart F, Van Essen T, Patton M, Paterson J, Scambler PJ. Spectrum of findings associated with interstitial chromosome 22q11 deletions: a European collaborative study. J Med Genet 1997;34: $798-804$.

12. McDonald-McGinn DM, Kirschner R, Goldmuntz E, Sullivan K, Eicher P, Gerdes M, Moss E, Solot C, Wang P, Jackobs I, Handler S, Knightly C, Heher K, Wilson M, Ming JE, Grace K, Driscoll D, Pasquariello P, Randall P, LaRossa D, Emanuel BS, Zackai EH. The Philadelphia story: the 22q11.2 deletion: report on 250 patients. Genet Couns 1999;10:11-24.

13. Vantrappen G, Deviendt K, Swillen A, Rommel N, Cogels A, Eyskens B, Gewillig M, Feenstra L, Fryns JP. Presenting symptoms and clinical features in 130 patients with the velo-cardio-facial syndrome: the Leuven experience. Genet Couns 1999;10:3-9.

14. Davidson A, Khandelwal M, Punnett HH. Prenatal diagnosis of the 22q11 deletion syndrome. Prenat Diagn 1997;17:380-383.

15. Levy-Mozziconacci A, Piquet C, Heurtevin PC, Philip N. Prenatal diagnosis of 22q11 microdeletion. Prenat Diagn 1997;17:1033-1037.

16. Raymond FL, Simpson JM, Mackie CM, Sharland GK. Prenatal diagnosis of 22q11 deletions: a series of five cases with congenital heart defects. J Med Genet 1997;34: 679-682.

17. Garcia-Heras J, Rao PN, Stettler RW, Huslig M, Smart RL, Petttenati MJ. Prenatal detection of a deletion 22q11 by FISH. Prenat Diagn 1998;18:411413.

18. Portnoi M-F, Joye N, Gonzales M, Demczuk S, Fermont L, Gaillard G, Bercau G, Morlier G, Taillemite J-L. Prenatal diagnosis by FISH of 22q11 deletion in two families. J Med Genet 1998;35:165-168.

19. Paladini D, Pacileo G, Palmieri S, Russo MG, Conti A, Piccola BD, Martinelli, P. Prenatal diagnosis of 22q11 microdeletion in a fetus with a conotruncal heart defect. Ultrasound Obstet Gynecol 1998;11:68-70.

20. Saliba Z, Le Biodis J, Sidi D, Kachaner J, Bonnet D. Prenatal detection of tetralogy of Fallot with origin of the left pulmonary artery from the ascending aorta in a familial 22q11 microdeletion. Prenat Diagn 1999;19:260-262.

21. Hatchwell E, Long F, Wilde J, Crolla J, Temple K. Molecular confirmation of germ line mosaicism for a submicroscopic deletion of chromosome 22q11. Am J Med Genet 1998;78:103-106. 22. Driscoll DA, Randall P, McDonald-McGinn DM, Zackai EZ, Li M, Emanuel BS, LaRossa D. Are 22q11.2 chromosomal deletions a major cause of isolated cleft palate? Paper presented at annual meeting of the American Cleft Palate-Craniofacial Association, Tampa, FL, 1995.

23. Devriendt K, Van Schoubroeck D, Eyskens B, Vantrappen G, Swillen A, Gewillig M, Dumoulin M, Moerman P, Vandenberghe K, Fryns JP. Polyhydramnios as a prenatal symptom of the DiGeorge/velo-cardio-facial syndrome. Prenat Diagn 1998;18: $68-72$.

24. Goodship J, Robson SC, Sturgiss S, Cross IE, Wright C. Renal abnormalities on obstetric ultrasound as a presentation of DiGeorge syndrome. Prenat Diagn 1997; $17: 867-870$ 
25. Driscoll DA, Li M, Chien P, Capuano S, Zackai EZ, McDonald-McGinn DM, Christensen KM, Cuneo BF, Saal HM, Gold R, Spector EB, Emanuel BS, Budarf ML. Familial 22q11 deletions: phenotypic variability and determination of deletion boundaries by FISH. Am J Hum Genet 1995;57(Suppl):A163.

26. Leana-Cox J, Pangkanon S, Eanet KR, Curtin MS, Wulfsberg EA. Familial DiGeorge/velocardiofacial syndrome with deletions of chromosome area 22q11.2: report of five families with a review of the literature. Am J Med Genet 1996;65:309-316.

27. Lazanakis M, Rodgers $\mathrm{K}$, Economides DL. Increased nuchal translucency and CATCH 22. Prenat Diagn 1998;18:507-510.

28. Iwarsson E, Ahrlund-Richter KL, Inzunza J, Fridstrom M, Rosenlund B, Hillensjo T, Sjoblom P, Nordenskjold M, Blennow E. Preimplantation genetic diagnosis of $\mathrm{Di}$ George syndrome. Mol Hum Reprod 1998;4:871-875.

29. Driscoll DA, Budarf ML, Emanuel BS. Antenatal diagnosis of DiGeorge syndrome. Lancet 1991;338:1390.

30. Driscoll DA, Emanuel BS, Mitchell LE, Budarf ML. PCR assay for screening patients at risk for 22q11.2 deletion. Genet Test 1997;1:109-113.

31. Bonnet D, Cormier-Daire V, Kachaner J, Szezepanski J, Souillard P, Sidi D, Munnich A, Lyonnet S. Microsatellite DNA marker s detects 95\% of chromosome 22q11 deletions. Am J Med Genet 1997;68:182-184

32. Moss EH, Batshaw ML, Solot CB, Gerdes M, McDonald-McGinn DM, Driscoll DA Emanuel BS, Zackai EH, Wang PP. Psychoeducational profile of the 22q112 microdeletion: a complex pattern. J Pediatr 1999;134:193-198.

33. Gerdes M, Solot C, Wang PP, Moss EM, LaRossa D, Randall P, Goldmuntz E, Clark BG, Driscoll DA, Jawad A, Emanuel BS, McDonald-McGinn DM, Batshaw ML, Zackai EZ. Cognitive and behavioral profile of preschool children with chromosome 22q11.2 deletion. Am J Med Genet 1999;85:127-133.

34. Daw SCM, Taylor C, Kraman M, Call K, Mao J, Schuffenhauer S, Meitinger T, Lipson T, Goodship J, Scambler P. A chromosome region of 10p deleted in DiGeorge and velocardiofacial syndromes. Nat Genet 1996;13:458-460.

35. Gottlieb S, Driscoll DA, Punnett H, Sellinger B, Emanuel BS, Budarf ML. Characterization of chromosome 10p deletions associated with DiGeorge syndrome suggests two non-overlapping regions contribute to phenotype. Am J Hum Genet 1998; 62:495-498.
36. Tsai CH, Van Dyke DL, Feldman GL. Child with velocardiofacial syndrome and $\operatorname{del}(4)(q 34.2)$ : another critical region associated with a velo-cardio-facial syndromelike phenotype. Am J Med Genet 1999;82:336-339.

37. Kurahashi H, Nakayama T, Osugi Y, Tsuda E, Masuno M, Imaizumi K, Kamiya T, Sano T, Okada S, Nishisho I. Deletion mapping of 22q11 in CATCH22 syndrome: identification of a second critical region. Am J Hum Genet 1996;58:1377-1381.

38. Rausch A, Pfeiffer RA, Leipold G, Singer H, Tigges M, Hofbeck M. A novel 22q11.2 microdeletion in DiGeorge syndrome. Am J Hum Genet 1999;64:658-666.

39. Saitta S, McGrath JM, Mensch H, Shaikh TH, Zackai EH, Emanuel BS. A 22q11.2 deletion that excludes UFD1L and CDC45L in a patient with conotruncal and craniofacial defects [Letter]. Am J Hum Genet 1999;65:562-566.

40. McQuade L, Christodoulou J, Budarf M, Sachdev R, Wilson M, Emanuel B, Colley A. Patient with a 22q11.2 deletion with no overlap of the minimal DiGeorge critical region (MDGCR). Am J Med Genet 1999;86:27-33.

41. Yamagishi H, Garg V, Matsuoka R, Thomas T, Srivastava D. A molecular pathway revealing a genetic basis for human cardiac and craniofacial defects. Science 1999; 283:1158-1161.

42. Wadey R, McKie J, Papapetrou C, Sutherland H, Lohman F, Osinga J, Frohn I, Hofstra R, Meijers C, Amati F, Conti E, Pizzuti A, Dallapiccola B, Novelli G, Scambler P. Mutations of UFD1L are not responsible for the majority of cases of DiGeorge syndrome/velocardiofacial syndrome without deletions within chromosome 22q11 [Letter]. Am J Hum Genet 1999;65:247-249.

43. Hess DB, Hess LW, editors. Fetal echocardiography. 1st ed. Stamford: Appelton \& Lange, 1999.

44. Carlson C, Sirotkin H, Pandita R, Molecular definition of 22q11 deletions in 151 velo-cardio-facial syndrome patients. Am J Hum Genet 1997;61:620-629.

45. Kerstjens-Frederikse WS, Kurahashi H, Driscoll DA, Budarf ML, Emanuel BS, Beatty B, Scheidl T, Siegel-Bartelt J, Henderson K, Cytrynbaum C, Nie G, Teshima I. Microdeletion 22q11.2: clinical data and deletion size. J Med Genet 1999;36:721723.

46. Okada S, Nishisho I. Another critical region for deletion of 22q11: a study of 100 patients. Am J Med Genet 1997;72:180-185. 